\title{
BMJ Global Health Paediatric and obstetric outcomes at a faith-based hospital during the 100-day public sector physician strike in Kenya
}

Mary Beth Adam, ${ }^{1}$ Sarah Muma, ${ }^{1}$ Jecinter Achieng Modi, ${ }^{1}$ Mardi Steere, ${ }^{1}$ Nate Cook, ${ }^{1}$ Wayne Ellis, ${ }^{1,2}$ Catherine T Chen, ${ }^{1}$ Arianna Shirk, ${ }^{1}$ John K Muma Nyagetuba, ${ }^{1}$ Erik $\mathrm{N}$ Hansen ${ }^{1}$

To cite: Adam MB, Muma S, Modi JA, et al. Paediatric and obstetric outcomes at a faithbased hospital during the 100-day public sector physician strike in Kenya. BMJ Glob Health 2018;3:e000665. doi:10.1136/ bmjgh-2017-000665

Handling editor Seye Abimbola

MBA and ENH contributed equally.,

SM, JAM, MS, NC, WE, CTC, AS and JKMN contributed equally.

Received 1 December 2017 Revised 19 March 2018 Accepted 20 March 2018
Check for updates

${ }^{1}$ Department of Pediatrics, AIC Kijabe Hospital, Kijabe, Kiambu, Kenya

${ }^{2}$ Pediatrics, Howard Hughes Medical Institute, Indiana University School of Medicine, Indianapolis, Indiana, USA

Correspondence to Dr Mary Beth Adam mary.b.adam@gmail.com

\section{ABSTRACT}

Published reviews of national physician strikes have shown a reduction in patient mortality. From 5 December 2016 until 14 March 2017, Kenyan physicians in the public sector went on strike leaving only private (not-for-profit and for-profit) hospitals able to offer physician care. We report on our experience at AIC-Kijabe Hospital, a not-forprofit, faith-based Kenyan hospital, before, during and after the 100-day strike was completed by examining patient admissions and deaths in the time periods before, during and after the strike. The volume of patients increased and exceeded the hospital's ability to respond to needs. There were substantial increases in sick newborn admissions during this time frame and an additional ward was opened to respond to this need. Increased need occurred across all services but staffing and space limited ability to respond to increased demand. There were increases in deaths during the strike period across the paediatric medical, newborn, paediatric surgical and obstetric units with an OR (95\% Cl) of death of 3.9 (95\% Cl 2.3 to 6.4$), 4.1$ (95\% Cl 2.4 to 7.1$), 7.9$ (95\% Cl 3.2 to 20$)$ and $3.2(95 \% \mathrm{Cl} 0.39$ to 27), respectively. Increased mortality across paediatric and obstetrical services at AIC-Kijabe Hospital correlated with the crippling of healthcare delivery in the public sector during the national physicians' strike in Kenya.

\section{INTRODUCTION}

Kenya's recent physician strike was focused on public sector facilities and encompassed work by government-employed specialist consultant physicians, medical officers (licensed physicians having completed an internship training year) and trainees (medical interns and registrars) at these facilities. The strike lasted 100 days, from 5 December 2016 to 14 March 2017..$^{1}$ Service delivery in the public sector was further reduced in December due to the national nurses' union having also initiated a strike on the same start date in December. The nursing strike was officially resolved by the end of December, but referral facilities where an expectant mother could deliver via caesarean section remained unmanned or staffed only by physicians in management

\section{Key questions}

What is already known?

- Universal healthcare coverage is one of the sustainable development goals and considered a universal mandate by the WHO and Kenya, where the constitution states it is the right of Kenyan citizens to receive the highest level of healthcare possible.

- Broad scale strikes by healthcare workers, especially in health systems where the only financially accessible option for the poor is the government system, has significant potential to limit access necessary healthcare services, especially where life-saving emergency caesarean section is limited.

- Reports of industrial action or physician strikes identified in a PubMed search $(n=22)$ did not show increased mortality during the strike periods.

\section{What are the new findings?}

- This study is the first to describe an increase in patient mortality associated with a national physicians' strike.

- Industrial action by physicians during which emergency and essential services are substantially reduced or withheld at a countrywide scale likely results in increased mortality.

- This is the only report of an industrial action by physicians' where such a broad scale shutdown of both elective and emergency services was demonstrated.

- Patient demand overwhelmed the ability of faith-based hospitals, the next level of financially accessible health care services, to respond.

positions. Some public sector healthcare facilities remained marginally functional as they were staffed by clinical officers and/or nurses. Many other facilities simply closed during the strike. Neither the doctors' union nor striking government physicians made substantive provisions for delivery of emergency or essential healthcare services, leaving 'private' 


\section{Key questions}

\section{What do the new findings imply?}

- Government needs to address healthcare professionals' concerns in order to mitigate unnecessary suffering especially when vast populations are primarily served by the government healthcare sector.

- Healthcare professionals need to address ethical issues potentially present in broad scale industrial action and identify ways to continue to protest, yet still provide essential lifesaving services as part of their professional mandate.

healthcare facilities, including faith-based organisations, the only options for access to healthcare in the country. Kenya's constitution aims for each citizen in Kenya to have the right to the highest attainable standard of health. ${ }^{2}$ The strike and the resulting decrease in healthcare accessibility during an extensive time period arguably limited equitable, affordable and quality healthcare services for many Kenyan citizens.

The WHO Constitution states that, '...the highest attainable standard of health is a fundamental right of every human being' ${ }^{3}$ This fundamental right is at risk when there is a functional failure of the healthcare system to deliver necessary services. Failures of the health system can occur in times of catastrophic overload, as during the Ebola crisis and during times of chaos and insecurity as a result of armed conflict. Peacetime non-epidemic concerns about failures of public health systems have well-publicised with one example being the UK Junior Doctors strike. ${ }^{4}$ Healthcare worker strikes pose a unique non-epidemic and non-conflict scenario where existing health systems can fail to provide 'the highest attainable standard of health' and therefore potentially deny this fundamental right.

In countries where the majority of care is delivered by a public health system, a healthcare workers strike can cause substantial disruptions, especially for the poor who are particularly vulnerable given their inability to pay high costs in the private sector. The potential impact of a healthcare workers' strike varies depending on the scope, duration, availability of essential life-saving services, range of medical cases affected and alternative options for accessing healthcare. ${ }^{5-7}$ In the African context, faithbased and private facilities provide an alternate source of care to that of the public sector. But even with subsidised costs, care at faith-based hospitals is more expensive than government facilities and costs remain a significant barrier to care for the poorest segment of the population.

We report the experience of Africa Inland Church-Kijabe Hospital (AICKH), a faith-based facility, which continued to provide care during the 100-day physician strike. ${ }^{8}$

\section{CONTEXT: KIJABE HOSPITAL AND THE STRIKE}

AIC-Kijabe Hospital $^{9}$ has been serving the poor and vulnerable in the Rift Valley of Kenya for more than 100 years. It is a 363-bed facility that performs between
9000 and 10000 surgical procedures annually and sees over 180000 outpatients per year. The institution has grown from a small mission outpost into a major tertiary care referral hospital and training centre. Half of the staff physicians are Kenyan and half are expatriate volunteers. Paediatric surgical care and training at AICKH occurs in partnership with BethanyKids, a non-profit faith-based organisation focused on children with surgical problems. The newborn nursery at AICKH only admits sick infants under 1 month of age.

\section{Description of routine data collection and morbidity and mortality review process for quality improvement}

Routine data on the number of admissions and deaths of newborn and paediatric medical patients, paediatric surgical admissions, operations and postoperative mortalities and obstetric patients are collected. Routine data collection and review procedures for all sick newborns admitted to the sick newborn nursery and paediatric admissions include tracking the date of admission, date of discharge or death, primary cause of death, key diagnoses, results from blood and other cultures, number of days in intensive care or high care units (like sick newborn units), need for phototherapy and other known complications via a password protected electronic database maintained by the consultant paediatricians. The paediatric general surgery service and the obstetric service maintain both electronic and a paper copy of admissions, operative procedures and postoperative morbidities and mortalities for all patients. All complications and deaths are reviewed in each clinical unit's routine mortality and morbidity review cycle to identify potential areas for quality improvement.

We examined data for newborn and paediatric medical patients and paediatric surgery patients during the 12-month period prior to the national physicians' strike, while obstetric data were available for 3 months immediately prior to the strike. We also examined data for all four services during the four calendar months, December 2016, January, February and March 2017, encompassed by the strike. These months were chosen since data are collected on a calendar-month basis. While the physician strike officially began 5 December, an unofficial 'go slow' mandate was in place within the public sector resulting in transfers from other facilities prior to, and in anticipation of, the formal walkout. The physician strike officially continued through 14 March 2017; however, we include the entirety of March as a strike month since all government physicians did not immediately return to work and patients remained uncertain of government service availability. Poststrike data were collected across services for the months of April and May 2017 as a national government nurses' strike began in June 2017.

\section{CLINICAL DEMAND AND HOSPITAL RESPONSE DURING THE STRIKE}

Throughout the duration of the strike, the clinical demand of patients presenting to AICKH, exceeded the 


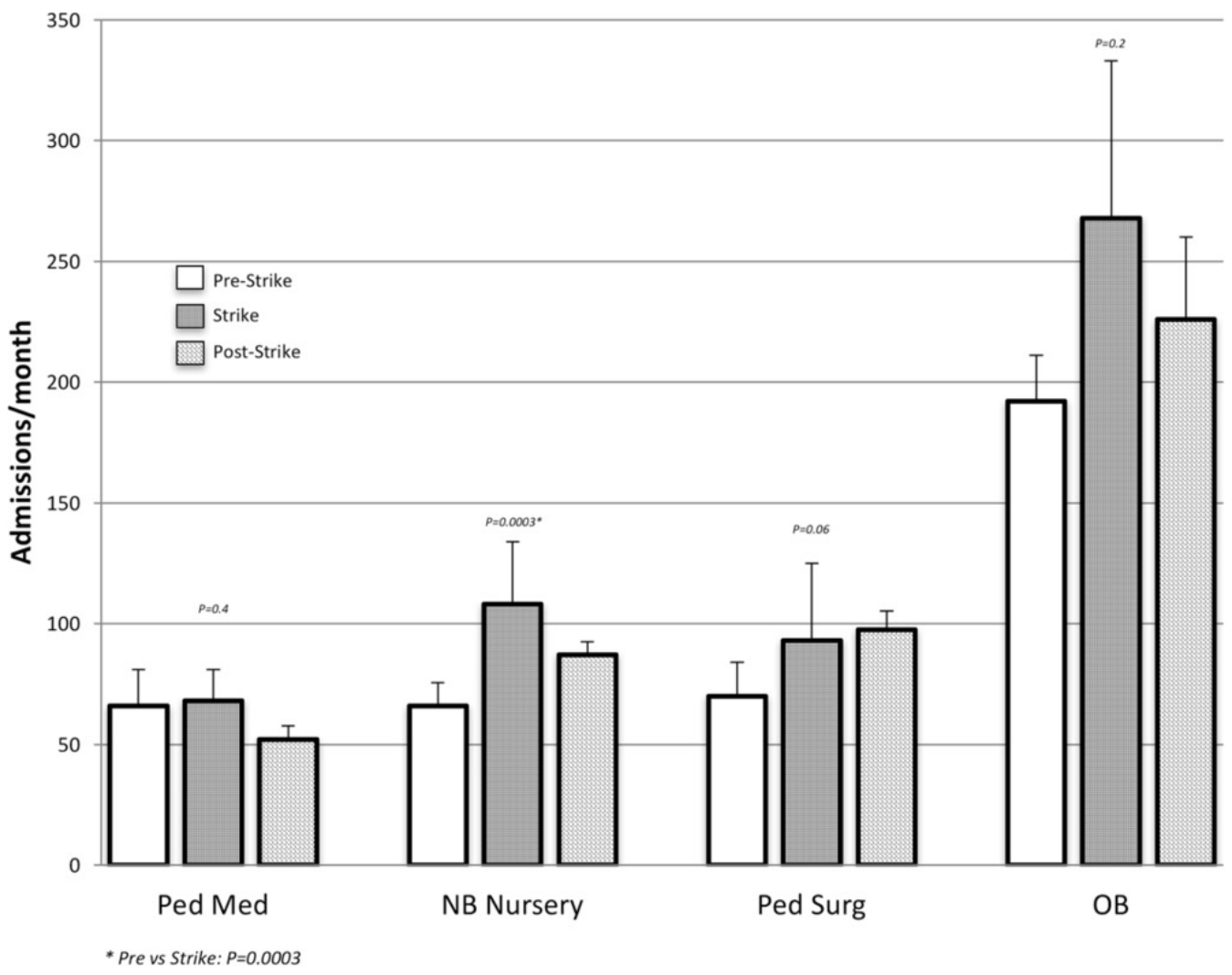

Figure 1 Average monthly admissions by unit before, during and after the strike.

hospital's capacity to respond and options to transfer or refer patients were rare to none. As such, AICKH systematically refused referral admissions from outside institutions. We do not have data on the number of patients turned away. In order to expand capacity, an administrative decision was made to open and staff an

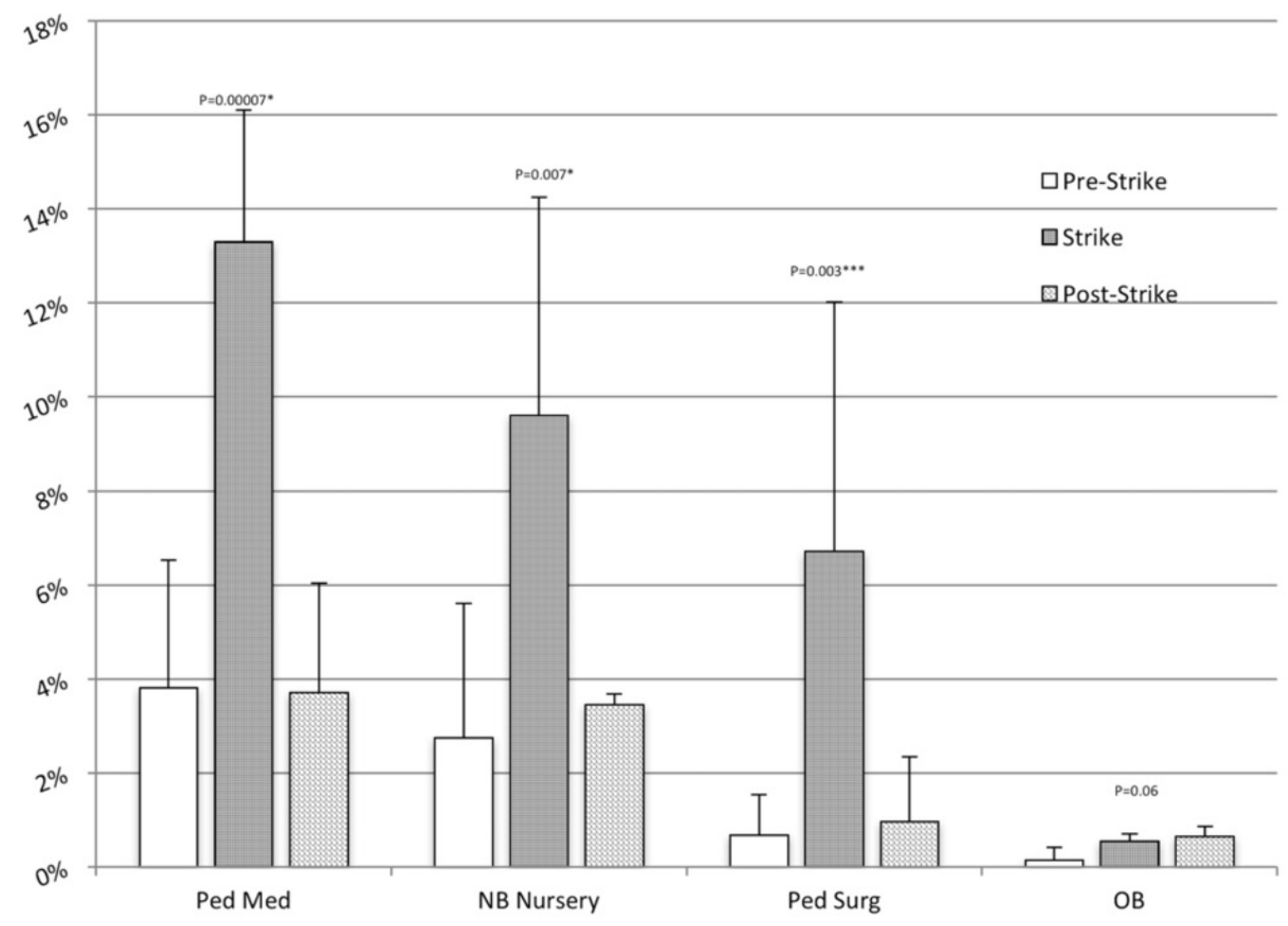

*Pre vs Strike: $P=0.00006$, Post vs Strike: $P=0.003 ;{ }^{* *}$ Pre vs Strike: $P=0.006 ;{ }^{* * *}$ Pre vs Strike: $P=0.002, P$ ost vs Strike: $P=0.05$

Figure 2 Monthly death rate by unit before, during and after strike. 
additional room for sick inborn newborns, as this was the area of greatest need. There was neither room nor staff to open additional paediatric beds. A de facto system of mass casualty style triage was effected to establish highest priority admissions and automatic referrals of presenting patients based on bed availability in all departments each day. Overload and inability to care for more sick newborns, limited our ability to respond to the demand of women in premature labour or with high-risk pregnancies, even though the hospital added beds for sick newborns. Obstetric admissions were also intermittently closed during the strike due to inability to care for any additional obstetric patients.

The physician staffing, including specialty trainees, at AICKH remained stable throughout the duration of the strike with the exception of the loss of government-sponsored medical officer interns $(n=10)$. Clinical officers $(\mathrm{CO})$, functioning as midlevel physician extenders, also continued alongside the physicians, nurses and ancillary staff at AICKH to provide care to as many sick children and pregnant women as feasible while taxing the already limited resources of the hospital infrastructure.

The provision of services remained intact, being limited only by bed space across all acuity levels of care. With only five ventilated beds for the entire hospital and an additional six monitored 'high dependency unit' (HDU) paediatric beds, there was not enough capacity to provide the ideally desired acuity of care for all paediatric patients. The de facto system of mass casualty style triage included decisions made not to escalate care for those children whose prognosis was most grim in an attempt to offer the extremely limited high acuity care to others with improved prognoses.

\section{KIJABE EXPERIENCE BEFORE, DURING AND AFTER THE STRIKE}

One-way analysis of variance (ANOVA) with post hoc Tukey honest significant difference (HSD) tests, ORs with 95\% CIs and effect sizes were used to compare prestrike, strike and poststrike data within clinical service units. ${ }^{1011}$

The volume of patients during the strike increased and patient demand exceeded the ability to admit patients. The average number of admissions in the sick newborn nursery service increased during the strike and decreased after the strike (figure 1). A difference in the average monthly number of deaths was seen in all units across the prestrike, strike and poststrike time periods. The monthly rate of deaths also increased on the sick newborn nursery service, the paediatric medical service and paediatric surgical service during the strike (figure 2). In the sick newborn and paediatric medical services, there was an approximate fourfold increase in deaths during the strike and a nearly eightfold increase in the paediatric surgical service. In obstetrics, there was approximately a threefold increase in monthly maternal deaths but this was not statistically significant (table 1). Effect size was moderate in the sick newborn nursery, paediatric ward and paediatric surgery service at 2.7, 3.3 and 5.1, respectively

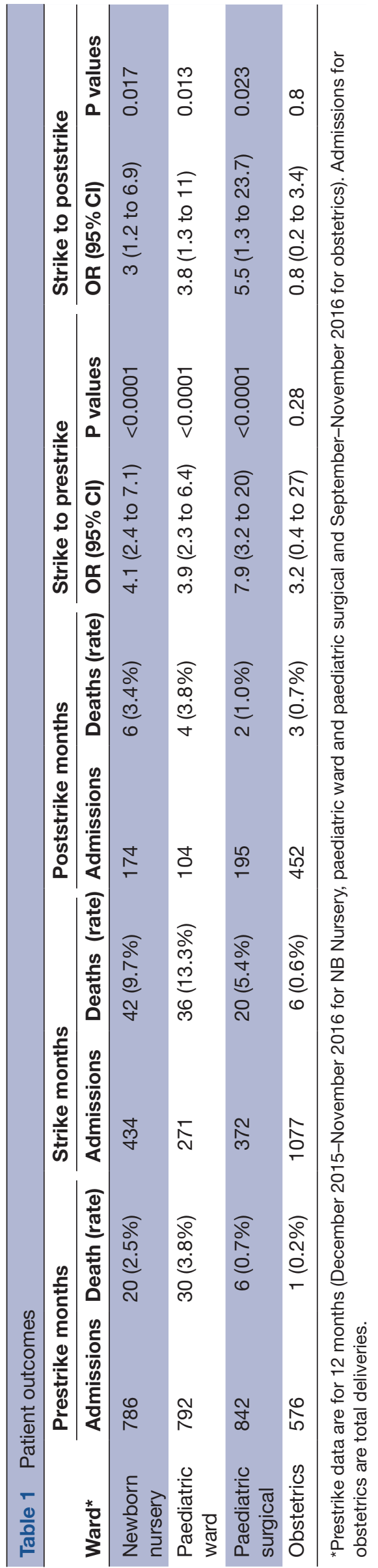


(table 2). ANOVA of each service demonstrated meaningful change in each time period for all services except obstetrics (table 2). The numbers in obstetrics were not large enough to be statistically significant, but the trend was in the same direction.

\section{THE IMPACT OF THE STRIKE AT KIJABE HOSPITAL}

The experience of the sick newborn, paediatric medical, paediatric surgical and obstetric services at AIC-Kijabe Hospital during the national physicians' strike in Kenya during the months of December 2016-March 2017 demonstrates a significant negative impact on patient survival. This is in contrast to the stable or reduced mortality rates reported by Cunningham et al in which they reviewed doctor strikes over a 40-year period along with the coinciding mortality figures. They concluded that physician strikes are associated with a reduced mortality rate. ${ }^{12}$ In all the cases reviewed, the strike modality implemented reduced care but continued to offer emergency and life-saving care. ${ }^{12}$ In the Los Angeles, California, USA, strike experience, surveys of the population indicated people either had access to their usual care sources or access to open emergency rooms. ${ }^{13}$ In the Israeli experience, striking doctors staffed emergency rooms as on holidays and weekends and in major population centres impromptu aid stations were staffed by physicians. ${ }^{14-16}$ Bhuiyan and Muchowski reported a decrease in mortality and admissions during a 20-day physician strike in a single province in the Republic of South Africa at the lone functioning referral centre. ${ }^{17}$ In this South African experience, emergency services at the government referral hospital were functioning.

The strike in Kenya differed from the strikes reported by Cunningham and others in that the public sector was crippled in its ability to offer emergency and life-saving care, even though some management level physicians in the government stepped in to do clinical care. Indeed, the Secretary General of the Kenya Medical Practitioners Pharmacists and Dental Union publically stated, 'Kenyans should not expect any emergency services in hospitals, including Kenyatta National Hospital' (KNHKenya's premier public referral and teaching centre). ${ }^{18}$ On the fifth day of the strike, 290 specialist physicians at Kenyatta National Hospital joined the strike. As an emergency measure, a few physicians from the Kenya military were deployed to KNH. ${ }^{19}$ Children presenting to AICKH with medical or surgical problems during the strike were 4-8 times more likely to die than those who presented in the 12 months prior to the strike.

While our single-hospital experience may not be generalisable across all non-governmental healthcare facilities in Kenya, published reports and personal communication from other faith based (Gainey M. Personal comunication, 2017) and private sector hospitals indicate our strike experience is not unique. ${ }^{20}{ }^{21}$ The Kenya public sector hospitals were non-functional. The Kenya clinical information network (CIN) was established in 2013 to collect data from public hospitals. ${ }^{22}$ Two thousand four hundred children were admitted to the 14 CIN government hospitals every month between January and November 2016. Yet, admissions dropped to less than $1 \%$ of previous levels at the 14 hospitals during the physicians' strike (Ayieko P. Personal communication, 2017) . A significant percentage of Kenya's population who were affected by the strike likely suffered and died as a result of no access to care. Patients who were either economically unable to afford the modest fees at faith-based institutions or who were limited by geography and were unable to travel to where other care was located had no options.

The question of whether, and under what circumstances, healthcare workers should take collective/ industrial action has been the subject of extensive ethical reflection. ${ }^{23-36}$ The WHO Director General, Tedros Ghebreyesus, considers universal health coverage an ethical mandate. ${ }^{37}$ Achieving universal healthcare coverage by 2030 is one of the sustainable development goals. ${ }^{38}$ Strikes by healthcare personnel certainly disrupt service delivery. Where essential lifesaving services like caesarean section, care for sick newborns and emergency surgery are unavailable for whatever reason, there is a substantial impact on universal coverage.

This report has several limitations. It is from a single centre. As such, we do not have regional or county-level data for reported mortalities across the three strike-related time periods. Given the fact that all government hospitals were crippled by the lack of physicians, patients who otherwise would have presented, and potentially died, at a government hospital now had no choice but to present to a non-government hospital. Therefore, our strike-related increase in mortality may be reflective of a de facto referral bias. There were no records of the number of patients turned away. The overwhelming number of patients and the inability to manage them required a mass casualty style triage system, but no scoring system for acuity of patients was in routine use. A mechanism to track the number of patients for whom we were unable to care and attempted to refer would have further substantiated the tremendous load carried by those physicians and staff who remained on duty during the days when the government system was crippled. AIC Kijabe Hospital's own nursing staff went on strike for 1 week in February and that disruption likely resulted in reduced ability to care for patients and may have contributed to negative outcomes that month. It also likely accounted for the overall reduced numbers of admissions across services since in February as the physician leadership implemented measures to prevent new admissions and to discharge all but the sickest of patients in the few days leading up to the local nursing strike. Fatigue due to overtime and overwork under stressful conditions may also have contributed. 


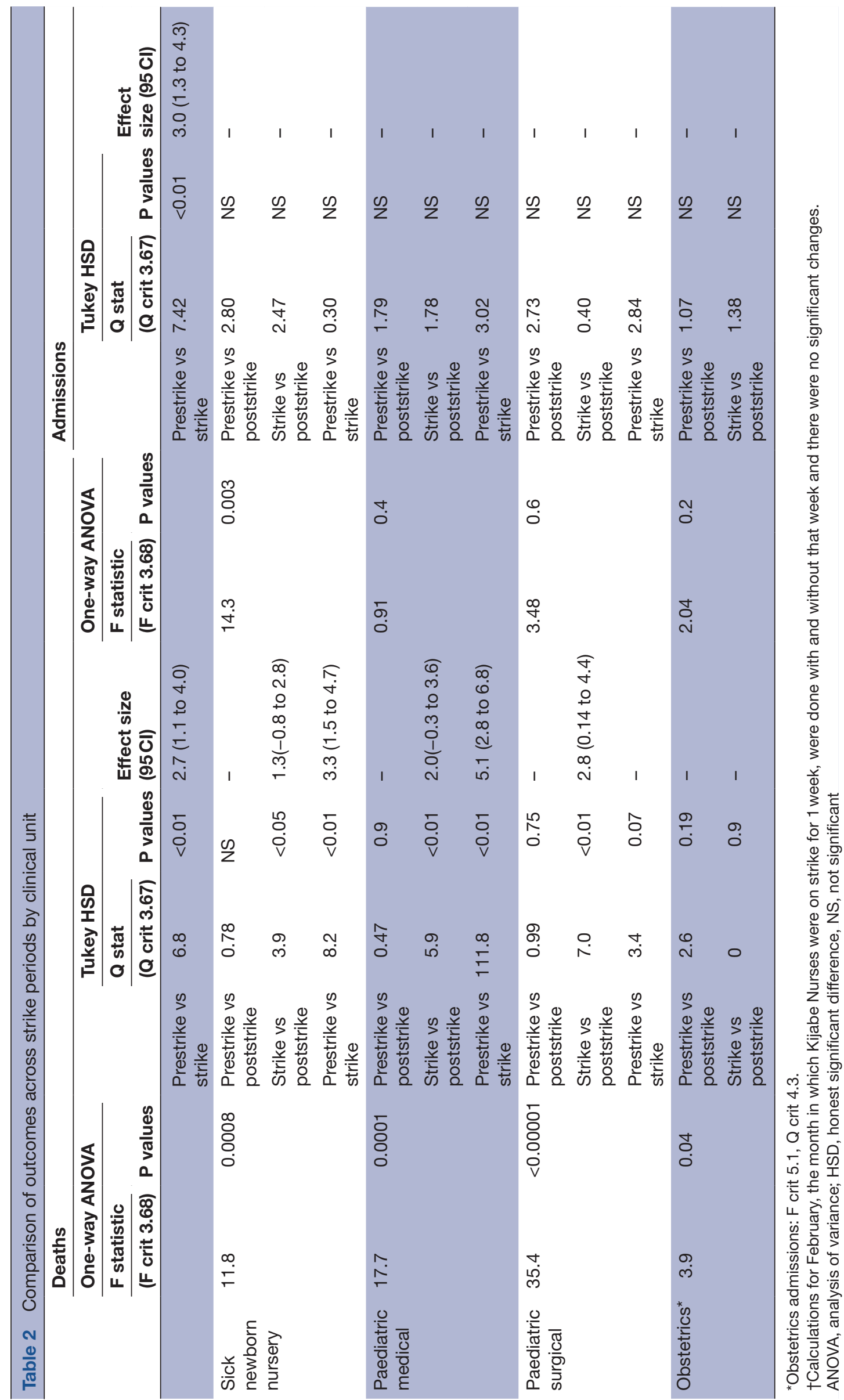




\section{CONCLUSION}

During the 100-day public sector physicians' strike in Kenya, obstetric, paediatric, neonatal and paediatric surgical deaths significantly increased at a faith-based hospital that continued to serve patients. The timing of deaths is correlated with the crippling of service delivery in the government sector during the strike.

\section{Data availability}

Data are available from the authors who maintain department-specific databases for purposes of routine morbidity and mortality audits for continuous quality improvement. Data are confidential and those requesting data would need to meet ethics committee criteria for researchers to have access to confidential data.

Acknowledgements All paediatric and obstetric clinical officers and nurses whose work during the incredible demands placed on them during the 100-day strike.

Contributors MBA contributed to the literature search, ethics review submission, creation and review of figures, study design and wrote the first draft of the manuscript. ENH was responsible for the literature review, creation and review of figures, study design and writing of manuscript. All authors gathered data, organised data base, assisted in the interpretation of data, reviewed relevant content, approved the final manuscript and accept responsibility for the integrity of the data.

Funding This research received no specific grant from any funding agency in the public, commercial or not-for-profit sectors.

Disclaimer The authors alone are responsible for the content of this paper and the views expressed do not necessarily reflect the views of the institutions with which they are affiliated.

Competing interests None declared.

Ethics approval Kijabe Hospital Ethics committee.

Provenance and peer review Not commissioned; externally peer reviewed.

Data sharing statement Data from this study are part of Kijabe Hospital patient records and the data are utilised for quality improvement purposes and general audit procedures as outlined in the manuscript. The sharing of de-identified aggregate data from the database could be made available by request with approval from the Kijabe Hospital Ethics committee.

Open Access This is an Open Access article distributed in accordance with the Creative Commons Attribution Non Commercial (CC BY-NC 4.0) license, which permits others to distribute, remix, adapt, build upon this work non-commercially, and license their derivative works on different terms, provided the original work is properly cited and the use is non-commercial. See: http://creativecommons.org/ licenses/by-nc/4.0/

(C) Article author(s) (or their employer(s) unless otherwise stated in the text of the article) 2018. All rights reserved. No commercial use is permitted unless otherwise expressly granted.

\section{REFERENCES}

1. Ministry of Health Kenya. Doctors end three month strike after strikeing deal with government Kenya. 2017. [cited 2017 March 14] http://www.health.go.ke/2017/03/doctors-end-three-month-strikeafter-striking-deal-with-govt/ (accessed 24 Jan 2018).

2. The Constitution of Kenya. $2010 \mathrm{http}: / /$ extwprlegs 1. fao.org/docs/ pdf/ken127322.pdf (accessed 17 Mar 2018).

3. Conference IH. Organization WH, ed. Constitution of the World Health Organization. New York: World Health Organization, 1946.

4. Goddard AF. Lessons to Be Learned From the UK Junior Doctors' Strike. JAMA 2016;316:1445-6.

5. Kirigia JM, Barry SP. Health challenges in Africa and the way forward. Int Arch Med 2008;1:27.
6. Njuguna J. Impact of Health Workers' Strike in August 2014 on Health Services in Mombasa County Referral Hospital, Kenya. $J$ Health Care Poor Underserved 2015;26:1200-6.

7. van Rensburg AJ, van Rensburg DJ. Nurses, industrial action and ethics: considerations from the 2010 South African public-sector strike. Nurs Ethics 2013;20:819-37.

8. Okeyo V, Merab E. The strike is over: but the pain, deaths and costs will be felt for many years: Daily Nation, 2017.

9. AlC Kijabe Hospital: Health Care to God's Glory [web page]. Kijabe Kenya: AIC Kijabe Hospital, 2017. http://kijabehospital.org/ (accessed 23 Jan 2018).

10. Medcalc easy to use statistical software version 17.4 Osten. Belgum: Medcalc, 2017. https://www.medcalc.org/calc/odds_ratio.php (accessed 27 Aug 2017).

11. Effect size calculator Durham University. Center for Evaluation and Monitoring. 2017 http://www.cem.org/effect-size-calculator (accessed 27 Aug 2017).

12. Cunningham SA, Mitchell $\mathrm{K}$, Narayan $\mathrm{KM}$, et al. Doctors' strikes and mortality: a review. Soc Sci Med 2008;67:1784-8.

13. James JJ. Impacts of the medical malpractice slowdown in Los Angeles County: January 1976. Am J Public Health 1979;69:437-43.

14. Slater PE, Ellencweig AY, Goldstein L, et al. Quality of emergency room care during the Israel doctors' strike. Public Health 1984;98:354-60.

15. Slater PE, Ever-Hadani P. Mortality in Jerusalem during the 1983 doctor's strike. Lancet 1983;2:1306.

16. Steinherz R. Death rates and the 1983 doctors' strike in Israel. Lancet 1984;1:107.

17. Bhuiyan M, Machowski A. Impact of 20-day strike in Polokwane hospital. SAMJ 2012:102. 18 August - 6 September 2010.

18. Kajilwa G. Crisis as doctors and nurses strike. Standard: Sect. Health, 2016. https://www.standardmedia.co.ke/health/article/ 2000225777/crisis-as-doctors-and-nurses-strike (accessed 24 January 2018).

19. Magale J. KDF deployed in Kenyatta National Hospital as doctors strike hit day 5. Tuko: Sect. Local News, 2016. https://www.tuko.co. ke/224191-kdf-deployed-kenyatta-national-hospital-doctors-strikehit-day-5.html\#224191 (accessed 24 Jan 2018).

20. Williams PCM. The reality of the mortality statistics of the nurses strike in Kenya. Lancet 2017;390:551.

21. The Lancet. Kenya's nurses strike takes its toll on health-care system. Lancet 2017;389:2350.

22. Ayieko P, Ogero M, Makone B, et al. Characteristics of admissions and variations in the use of basic investigations, treatments and outcomes in Kenyan hospitals within a new Clinical Information Network. Arch Dis Child 2016;101:223-9.

23. Adam MB. Physician Unions. In: Kilner J, Orr RD, Shelly J, eds. The changing face of healthcare. Grand Rapids, Eerdmans: Michigan, 1998:245-57

24. Brecher R. Striking responsibilities. J Med Ethics 1985;11:66-9.

25. Cruess RL, Cruess SR. Commentary: professionalism, unionization, and physicians' strikes. Acad Med 2011;86:86.

26. Fiester A. Physicians and strikes: can a walkout over the malpractice crisis be ethically justified? Am J Bioeth 2004;4:12-16.

27. Frizelle F. Is it ethical for doctors to strike? N Z Med J 2006:119.

28. Goold SD. Collective action by physicians: beyond strikes. Camb $Q$ Healthc Ethics 2000;9:498-503.

29. Hassen EK. Public service strike: Beyond cowboy bargaining: The South African Civil Society Information Service (SACSIS), 2010.

30. Jesani A. Health workers and strikes: ethics and rights. Iss Med Ethics 1998.

31. Keith SN. Collective bargaining and strikes among physicians. J Nat/ Med Assoc 1984;76:76.

32. Loewy EH. Of healthcare professionals, ethics, and strikes. Camb $Q$ Healthc Ethics 2000;9:513-20.

33. Ogunbanjo GA, Knapp van Bogaert D. Doctors and strike action: can this be morally justifiable? SA Fam Pract 2009:51.

34. Aacharya RP, Varghese S. Medical doctors' strike: an ethical overview with reference to the Indian context. J Clin Res Bioeth 2016;7.

35. Quinn R. When physicians strike. 13: ENT Today, 2017.

36. Thompson SL, Salmon JW. Strikes by physicians: a historical perspective toward an ethical evaluation. Int $J$ Health Serv 2006;36:331-54

37. Ghebreyesus TA. All roads lead to universal health care. Lancet Global Health 2017;2017.

38. Rumbold B, Baker R, Ferraz O, et al. Universal health coverage, priority setting, and the human right to health. Lancet 2017;390:712-4. 